\title{
El artista contemporáneo ante la transformación de su obra. El paso del tiempo y su efecto sobre la significación de la materia
}

\section{The contemporary artist in front of the transformation of his works. The elapse of time and its effect on materiality}

\author{
RoSARIO Llamas-PACHECO \\ Universidad Politécnica de Valencia \\ rllamas@crbc.upv.es
}

Recibido: 24 de febrero de 2015

Aprobado: 3 de junio de 2015

\section{Resumen}

El paso del tiempo tiene una repercusión inevitable sobre las obras de arte. En el caso del arte contemporáneo muchos de los valores estéticos, culturales o sociales presentes en las mismas, están vinculados a la apariencia y al uso premeditado de la materia. La transformación de la materia tiene una repercusión sobre la intención y el discurso estético, por ello, y ante la imposibilidad de impedir el cambio, se hace necesaria una profunda reflexión sobre el concepto de autenticidad de la obra de arte y sobre el concepto de ruina prematura. Por otro lado, gracias a la figura del artista contemporáneo es posible documentar la producción actual para determinar si la mutación de la materia afectará a lo esencial en las obras. En este sentido, el trabajo ha conseguido concretar, para el caso de varios artistas fundamentales del panorama español, qué aspectos deben, por ser esenciales, permanecer inmutables con el paso del tiempo.

Palabras clave: arte contemporáneo, materia, envejecimiento, ruina, autenticidad.

Llamas-Pachecho, R. (2016): El artista contemporáneo ante la transformación de su obra. El paso del tiempo y su efecto sobre la significación de la materia. Arte, Individuo y Sociedad, 28(2) 277-296

\begin{abstract}
The passage of time has an inevitable impact on artworks. In the case of many of the contemporary art aesthetic, cultural or social values present in them, are linked to the appearance and premeditated use of matter. His transformation has an impact on the intent and aesthetic discourse, so that a deep reflection on the concept of authenticity of the artwork or premature ruin is necessary. Moreover, thanks to the figure of the contemporary artist is possible to document the current production to determine if the mutations of matter affect the essential in their works. Thus, the work has achieved specific, in the case of several key Spanish artists, what aspects should, because they are essential, to remain unchanged over the years. Keywords: contemporary art, matter, aging, ruin, authenticity.
\end{abstract}


Sumario: 1. La figura del artista contemporáneo en el proceso de documentación de la obra, 2. Sobre las ruinas, lo auténtico, y los cambios en la materia de las obras, 3. La materia, la técnica y el paso del tiempo en la obra contemporánea, 4. La materia y su significación en la obra de José María Yturralde, 5. La materia y su significación en la obra de Miquel Barceló, 6. La materia y su significación en la obra de Juan Genovés, 7. La materia y su significación en la obra de Miquel Navarro, 8. La materia y su significación en la obra de Equipo Crónica, 9. Conclusiones. Referencias.

Este artículo recoge parte de los resultados de la investigación llevada a cabo en el proyecto "Conservación y Restauración de Arte no Convencional", financiado por el Ministerio de Economía y Competitividad, dentro del Programa Estatal de Investigación Científica y Técnica de Excelencia (2014-2017). Ref: HAR2013-41010-P.

\section{La figura del artista contemporáneo y el proceso de documentación de la obra}

El arte contemporáneo está vivo. No sólo en sentido figurado: también la vida real forma parte hoy en día de las obras de arte [Fig.1]. Esta afirmación da cuenta de los procesos de transformación y evolución sufridos en el terreno artístico tras la Segunda Guerra Mundial. Como fruto de estos procesos de transformación han aparecido una gran variedad de propuestas plásticas que han introducido elementos hasta ahora no presentes en el arte. Estos nuevos elementos, utilizados con una intención plástica o sensorial determinada, han planteado nuevos problemas para los estudiosos que pasan por el entendimiento del plano semántico de la materia, la aparición de ruinas prematuras, la reposición de partes o incluso, la reedición de los objetos dotados de "artisticidad".

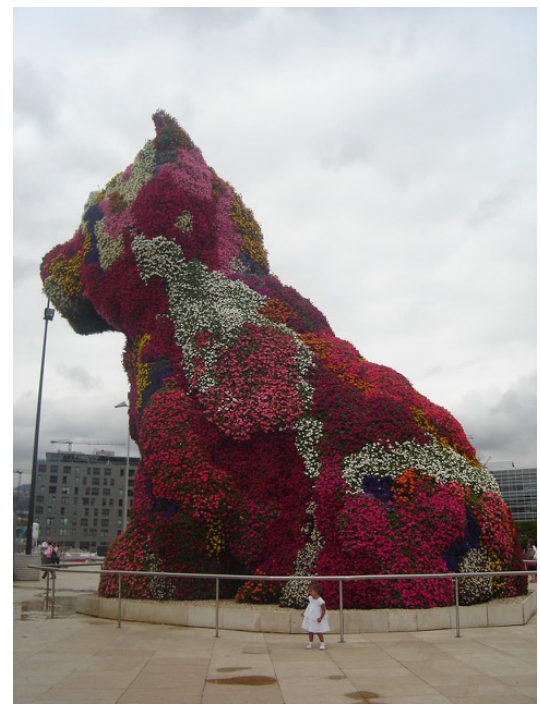

Figura 1. Jeff Koons, Puppy, 1992. Acero inoxidable, sustrato y plantas en floración, 1.240 x 830 × $910 \mathrm{~cm}$. Guggenheim Bilbao Museoa. Fotografía de la autora.

Uno de los objetivos de este estudio ha sido realizar una reflexión teórica sobre estos conceptos, pero llevándola al plano concreto de la historia del arte a través del contacto directo con algunos artistas representativos, de modo que quede recogida 
su opinión sobre cómo el paso del tiempo afectará a la significación de sus obras. En esta línea de trabajo, y entendida la necesidad y oportunidad de recoger el testimonio directo de los propios creadores, y tras haber realizado una serie de entrevistas personales, recogeremos su visión de lo que realmente constituye la esencialidad de las mismas, atendiendo especialmente a cuál es la relación que existe entre la idea y la materia y haciendo hincapié en la descripción, para cada caso, de la intención artística.

A través de las entrevistas se ha podido recopilar una gran cantidad de información que desde una perspectiva nueva, la del creador de la obra de arte, puede ser útil para entender las actuales propuestas plásticas y para conocer de primera mano cómo el artista percibe la transformación inevitable de su obra y cómo esta transformación podría o no, afectar a la significación artística.

Los conceptos de intención artística o significado de la obra se utilizan con poca precisión en la disciplina de la conservación del arte contemporáneo y necesitan ser definidos porque, como apunta Mieke Bal (2002:30-31):

El "significado" es uno de estos casos de concepto-palabra común, que oscila como si tal cosa entre la semántica y la intención. Dada esta flexibilidad que hace que la semántica parezca intención, uno de los objetivos...es plantear la idea de que la extendida predominancia del intencionalismo -la equiparación del significado con la intención del autor o el artista- con todos los problemas que éste conlleva, se debe a esta equiparación irreflexiva de las palabras y los conceptos.

Por otro lado, la obra de arte actual se ha convertido en un ente capaz de evolucionar ante la mirada, a veces perpleja, del espectador [Fig.2 y 3]. Este proceso de transformación es en muchas ocasiones premeditado, pues el artista crea su obra para un espacio concreto, un lugar y un momento de exhibición determinados, de los cuales será fruto. Sin embargo, como ocurre con las instalaciones, tras un periodo de tiempo, la idea puede volver a materializarse, produciéndose en este segundo momento cambios en la apariencia y en muchas ocasiones, hasta la sustitución de la materia prístina; y ello, con el conocimiento y consentimiento del autor [Fig.4].

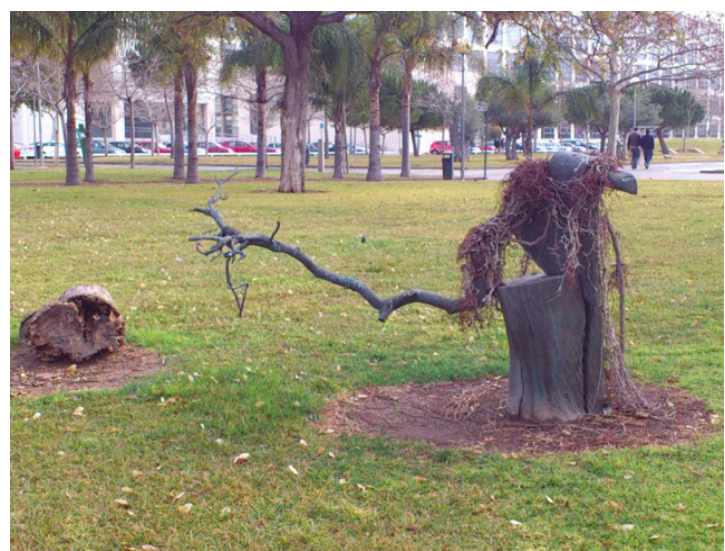

Figura 2. Miguel Molina, Murmullos del bosque, 2000. Metal y vegetación real. Fondo de arte de la Universidad Politécnica de Valencia. Fotografía realizada en febrero de 2013. Fotografía de la autora. 


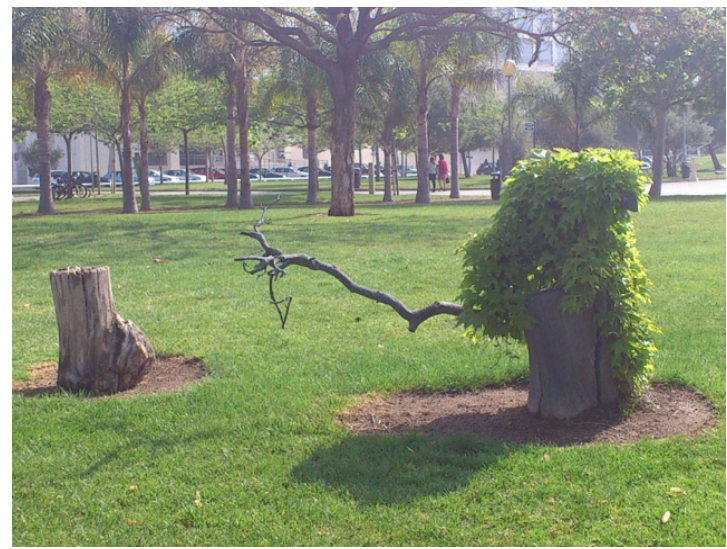

Figura 3. Miguel Molina, Murmullos del bosque, 2000. Metal y vegetación real. Fondo de arte de la Universidad Politécnica de Valencia. Fotografía realizada en abril de 2013. Fotografía de la autora.

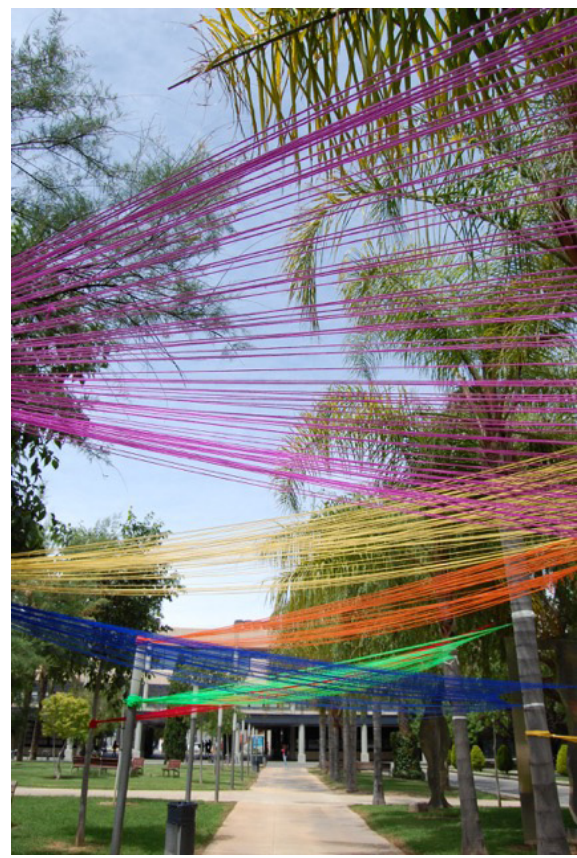

Figura 4. Instalación realizada en la Universidad Politécnica de Valencia en Junio de 2013.

La fibra textil es utilizada en el arte contemporáneo como el material base de la obra, y no como un mero soporte. Fotografía de la autora.

Resulta evidente la idoneidad de recopilar información sobre la intención plástica, el discurso estético y el universo intelectual del artista gracias a las entrevistas con los propios creadores, pero también es necesario recopilar información sobre cómo entienden qué es lo auténtico en su producción, lo verdaderamente esencial, lo inmutable, para definir en qué momento ésta podría convertirse en una ruina. También 
es necesario obtener información sobre cómo el envejecimiento y la transformación afectarán a las cuestiones semánticas de sus creaciones.

Por otro lado, esta metodología de trabajo viene siendo empleada desde hace años en diversos grupos y redes de investigación internacionales, el grupo internacional de trabajo INCCA (International Network for Conservation of Contemporary art), ha generado una base de datos con entrevistas de artistas que está accesible a los miembros investigadores, $\mathrm{y}$ ha publicado y puesto a disposición de los estudiosos diversos trabajos sobre cómo la figura del artista puede ser de utilidad en el momento de documentar la obra de arte.

Para analizar estas cuestiones hemos seleccionado algunos de los artistas más representativos a los que hemos tenido ocasión de entrevistar, de modo que este documento se convierta, además de en una reflexión teórica, en un testimonio de la intención y las directrices dadas por ellos mismos para el mejor entendimiento y disfrute de sus obras. Los artistas sobre los que hablaremos a continuación son Miquel Barceló, Miquel Navarro, Juan Genovés, José María Yturralde y Equipo Crónica a través de la entrevista realizada a su asistente Rosa Torres.

\section{Sobre las ruinas, lo auténtico, y los cambios en la materia de las obras}

Comenzaremos analizando el concepto de ruina, por lo que de especial conlleva para el caso del arte contemporáneo. ¿Puede una obra de arte reciente haberse convertido en una ruina? Cesare Brandi define el concepto de ruina como "[...] el caso extremo de una manufactura, reducida a testimonio apenas reconocible de una obra (o de un evento humano) pero ya incapaz - en el caso de una obra de arte- de ser reconducido a la "unidad potencial" sin convertirse en una copia o una falsificación de sí mismo y que, por lo tanto, puede ser sólo conservado, no restaurado" (Basile, 2007: 82).

Sin embargo, esta definición está dirigida notoriamente hacia el arte tradicional, pues adolece de una atención exclusiva hacia la materia, dejando de lado un aspecto absolutamente esencial para el caso del arte contemporáneo: la importancia de la idea que fue el motor de la obra y que para muchos artistas tiene la misma importancia o aún más, que la propia materia.

La teoría de Cesare Brandi aborda el problema de la ruina de la obra de arte apuntando que en ese estado la obra no puede ser intervenida más que en el sentido de la conservación. Sin embargo, para el arte contemporáneo el problema se amplía sensiblemente. De hecho, encontramos situaciones muy diversas en el caso del arte actual. Así, podríamos situarnos ante una obra cuya materia se hubiera visto alterada con el paso del tiempo de modo que ya no fuera capaz de facilitar su discurso: en este caso estaríamos ante una ruina, incluso aunque la degradación no fuera excesiva. Se trataría pues de una ruina conceptual, en tanto que el mensaje propuesto por el artista no llega al espectador a través de la materia degradada. Para este supuesto la definición de Brandi queda limitada, pues no estamos en presencia "[...] del caso extremo de una manufactura, del testimonio casi irreconocible de una obra", ya que podría únicamente haberse amarilleado una capa pictórica de color blanco, por ejemplo, o haberse arañado la superficie lisa, monocroma y aterciopelada de una obra de Yves Klein. 
Nos encontraríamos ante una materia no excesivamente degradada, pero cuya alteración habría afectado a los aspectos semánticos esenciales de la obra. Este es el caso de Prisma 4, de 1972 de José María Yturralde en la que, ante unas grietas en la superficie pictórica, el artista ha rehecho o reconstruido todas las capas de color. Para este artista, unas pequeñas grietas aparecidas en el perímetro de la obra como consecuencia del movimiento de unos clavos, la habría llevado al estado de ruina, hasta el punto de preferir lijar totalmente la superficie para volver a pintarla antes de verla, bajo su punto de vista, absolutamente degradada (Llamas, 2014: 220).

Podríamos desde aquí intentar precisar la definición de ruina para el caso del arte contemporáneo, tras haber entendido la importancia del plano conceptual para el artista, tras ponerlo en valor, y tras haber comprendido que incluso en obras donde la materia se convierte en protagonista, ésta suele ir cargada de una serie de valores semánticos, simbólicos (Muñoz, 2003: 49-58) y culturales que la sustancian y dotan de significación.

Por ello, ruina, para el caso del arte contemporáneo, podría definirse como el estado en el que la obra, tras el paso del tiempo, se sustenta en una materia que ha estado sometida a los efectos de los agentes físicos, químicos, biológicos y antropológicos de deterioro, de modo que ha llegado a un punto en que ya no es capaz de servir de sostén al discurso estético pretendido, por lo que el plano semántico se vería fuertemente afectado por la condición de la materia. Esta mala condición de la materia podría no ser excesivamente grave, y aún así afectar de manera irreversible al sentido de la misma. Muchos son los artistas que utilizan la expresión "la obra ya no funciona", refiriéndose a este problema y ante estados no excesivamente graves de deterioro.

Es importante señalar cuán importante es la figura del artista para determinar el punto en el que el estado de la materia empezaría a no ser aceptable, y cuán importantes son las entrevistas con los artistas contemporáneos que se llevan a cabo con la intención de documentar y tener recogidos, al menos para el caso de los más significativos, las cuestiones que hacen referencia a la esencialidad de las obras y a los efectos del paso del tiempo sobre las mismas, con el fin de conocer su repercusión sobre el plano semántico. El papel que el artista puede aportar en el proceso de entendimiento de la obra ya fue puesto en valor con anterioridad (Escohotado, 2007: 204).

Es probable que nos sorprendiéramos ante la poca importancia que el artista otorga en algunos casos a la materia, hasta el punto de proponer la sustitución de la misma. El caso de las instalaciones es un ejemplo, ya que muchos de sus elementos se sustituyen o modifican siendo los propios artistas quienes dan las directrices sobre qué es lo esencial a conservar y qué elementos no deben ser preservados, por no existir en este caso la necesidad de unicidad del objeto artístico.

Es obvio que nos encontramos ante nuevas situaciones que nos alejan de la obra aurática descrita por Benjamin (2003: 42-57), una obra en la que prevalece el "valor para el culto" y que está dotada de un aura y de un carácter irrepetible dada su singularidad. La autenticidad para Benjamin va ligada al aquí y al ahora, va ligada a la tradición, la cual ha llevado al objeto hasta el día de hoy, cabría añadir, con la apariencia prístina. 


\section{La materia, la técnica y el paso del tiempo en la obra contemporánea}

El paso del tiempo también es un factor que afecta a los propios artistas. Es posible encontrar, al comparar entrevistas con algunos artistas, que tras algunos años, la opinión sobre la intención de conservación, o sobre el tratamiento que debe darse a la materia, puede cambiar.

Es importante reflexionar en este punto sobre cómo afecta la temporalidad en los procesos de producción de significados. Como señala Huyssen (2002: 217237), en los últimos años se ha puesto el foco en la importancia de la memoria y la temporalidad en términos culturales. A partir de los años sesenta la búsqueda de identidad y la necesidad de definir la tradición, condujo hacia teorías de negación del arte y del individuo. Estaríamos según este autor ante el boom de la memoria, traducido en algunos casos en la elaboración de obras de tipo entrópico como Les Lieux de mémoire (Nora, 1984-1992), y en otros, ante una necesidad excesiva de musealización como recurso perpetuador de esta memoria.

Podría parecer que la necesidad de documentación de las obras se enmarca en esta última tendencia, la cual evidencia cierto miedo al olvido. Sin embargo, es necesaria la documentación de la intención del artista en un momento muy inicial a la creación de la obra ya que con el paso del tiempo, los propios artistas van evolucionando, y podrían cambiar esa intención. En este sentido, el testimonio temprano garantiza que la obra sea entendida, respetada, y en ocasiones, salvaguardada de su propio creador, ya que no son extraños los casos en que el propio artista ha retomado una obra y la ha rehecho en gran parte introduciendo un segundo momento de creación. En palabras de Gianni Colombo "[...] un autor se siente frustrado si se le pide que reconstruya pasivamente algo que ya había realizado y no puede permitirse ninguna evolución, ningún cambio o innovación en una experiencia artística pasada" (Gianni, 2005: 113).

Tampoco podremos empeñarnos en mantener inmutable la obra, pues como se ha apuntado, el paso del tiempo causará en ella un efecto inevitable. ¿Qué podríamos proponernos al documentarla lo más tempranamente posible? Quizá conocer, no cuál debería ser su estado permanente, pues esta permanencia es imposible, sino qué es aquello que constituye lo realmente importante para el artista, lo que afecta a su autenticidad y que debe permanecer inalterado.

Esta reflexión debe ser planteada al artista, que a menudo se enfrenta por primera vez con este tipo de cuestiones de índole teórico. En cualquier caso, no todas las entrevistas a los artistas adquieren el mismo grado de profundidad, al centrarse en cuestiones meramente técnicas. La documentación específica, centrada en los aspectos semánticos de la materia, y en la búsqueda de lo que verdaderamente constituye la autenticidad en cada caso, es de gran utilidad para el entendimiento de la historia del arte actual.

Es difícil encontrar un único punto de autenticidad en las obras, pero lo es aún más en el arte actual, pues desde el momento inicial de la creación, la obra podría haber sido concebida con el deseo de cambio o mutación premeditada de la materia. ¿Podríamos empeñarnos en mantener una instalación de panes sobre el mar en el estado en que se encontraba en el momento inicial? ¿Reside la autenticidad de la obra en la unicidad de la misma, en la originalidad de la mano del artista, en la originalidad de la materia prístina? Obviamente es necesario un cambio de paradigma que nos 
ayude a encontrar donde reside la autenticidad de unas obras en las que la materia que sirvió para concretar la idea, sólo existirá durante un periodo de tiempo determinado [Fig. 5].

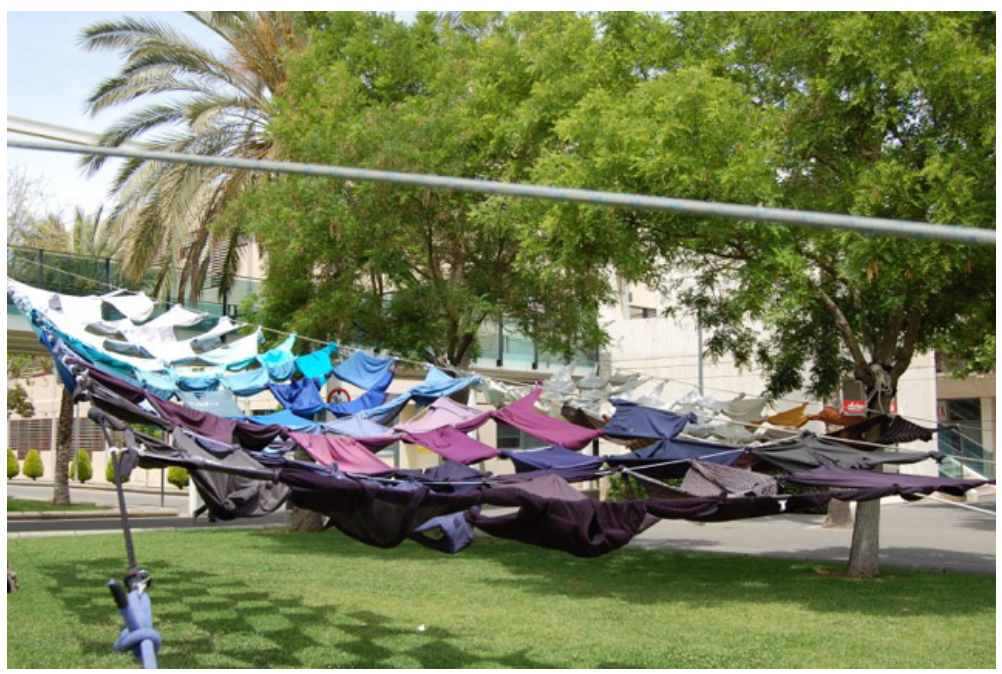

Figura 5. Instalación realizada en la Universidad Politécnica de Valencia en Junio de 2013. La materia que sirve para la concreción de la obra adquiere un segundo plano. Los elementos podrían ser sustituidos ante una nueva concreción de la idea. Fotografía de la autora.

\section{La materia y su significación en la obra de José María Yturralde}

En la década de los años sesenta el panorama artístico español no era capaz de concretar una alternativa a las corrientes afianzadas desde los años cincuenta. Tras la crisis del informalismo de los cincuenta, el crítico y pintor Juan Antonio Aguirre reunió un grupo de artistas que pretendieron dar una respuesta a la situación. Este grupo se reunió en 1967 y bajo el nombre de Nueva Generación aglutinó un grupo de artistas heterogéneo, que se dejó influenciar por el arte pop y el arte cinético (Guash, 1997: 257). Este grupo se dividió en dos tendencias, una figurativa y otra abstracta, más racionalista y constructiva. José María Yturralde se situó en esta segunda tendencia, la cual se caracterizó por el uso de la ciencia y algunas herramientas como los incipientes ordenadores para aumentar la capacidad creadora de los artistas. Su intención artística era equiparar los procesos artísticos a los procesos científicos sin dejar de interesarse por conocer los procesos de percepción del ser humano, por entenderlos y desarrollarlos, de manera que pudiera conseguirse la máxima comunicación con el espectador.

El discurso artístico de José María Yturralde en los setenta tenía un carácter marcadamente científico (Barreiro, 2009: 329) buscando lo objetivo a través de pocos datos, claros y concisos, de modo que se planteara el problema estético pretendido. El interés en muchas de sus obras se centra en el campo de la percepción, característica que ha perdurado a lo largo de los años (Aliaga/García, 1998: 305-307). 
En relación con la materia y la técnica, cabría diferenciar entre las obras de los primeros años de formación y las obras más recientes. En un primer momento, en sus figuras imposibles, creadas gracias al ordenador con la intención de explorar el espacio a partir de figuras bidimensionales y tridimensionales, Yturralde utilizó materiales industriales, colores fosforescentes, amarillo limón, rojos intensos de naturaleza sintética, que aportaban un carácter plano y homogéneo a las superficies. Más tarde creará sus estructuras volantes, objetos realizados con materiales ligeros como el aluminio y el nylon, con una naturaleza efímera.

Actualmente Yturralde produce obra pictórica de tinta plana o de degradación del color [Fig. 6], en las que utiliza colores brillantes y espectaculares, que pueden alterarse fácilmente si no se adoptan las medidas adecuadas de conservación preventiva.

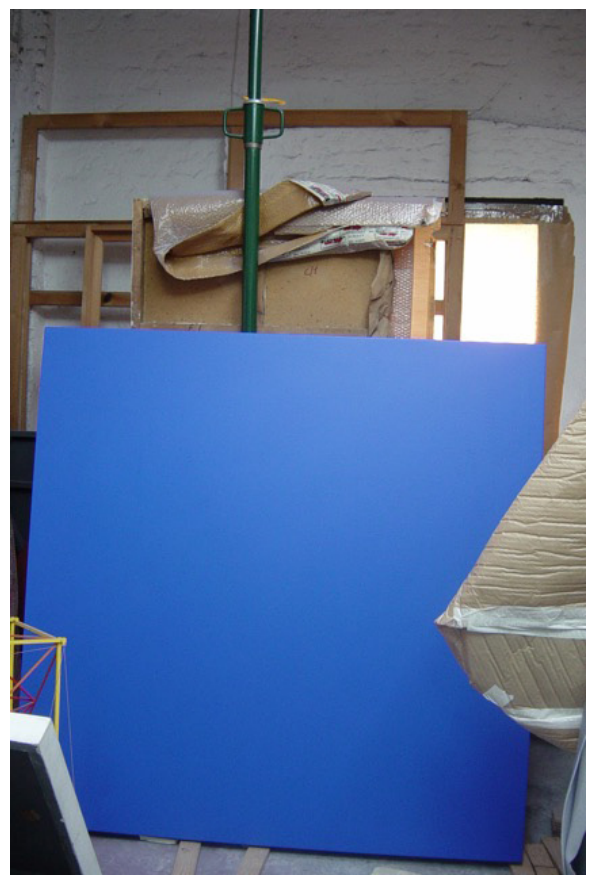

Figura 6. José María Yturrale, pintura monocroma en azul, formato cuadrado 1x1m. Puede apreciarse la fragilidad de la superficie. Los daños mecánicos sobre la misma causarían un grave problema de percepción, afectando gravemente al plano semántico. Fotografía de la autora.

Podemos concretar algunas cuestiones técnicas de su producción. Al preguntar al artista por los tipos de soportes que utiliza en sus creaciones, en una entrevista realizada por Ioseba Imanol Soraluze Herrera y Rosario Llamas, explica que pinta sobre lienzos. Según señala utiliza pintura acrílica que encarga al extranjero, a Holanda, Suiza o Francia, y en relación con las telas prefiere los lienzos ya imprimados, pero sobre la imprimación comercial que presentan aplica varias capas de gesso de la casa Lefranc y sobre ella utiliza los colores de la marca Lascaux ${ }^{\circledR}$. También señala que 
en los años setenta utilizaba óleos y pintura sintética industrial, concretamente de la casa Titán ${ }^{\circledR}$.

La técnica, el oficio, la materia en definitiva, adquieren para el artista una gran importancia pues persigue la calidad máxima de sus trabajos como él mismo señala: “[...] para mí la técnica significa que esté bien hecho el cuadro, y saber pintar bien una obra es algo que persigo y que no consigo aprender" (J.M. Yturralde, comunicación personal, 6 de mayo, 2006).

Es interesante, en relación con la significación de los materiales y técnicas del artista, el uso que hace del barniz, así como la preocupación por el aspecto que éste confiere a la superficie. Ante la necesidad de protección de sus obras se ve obligado a utilizarlo, pero dada la preocupación por obtener el acabado mate de las superficies se decanta por un barniz mate. Según señala el artista, utiliza barniz porque necesita proteger unas superficies tan delicadas, pero en ocasiones el barniz ha acabado afectando a la apariencia de las obras al haber sufrido oxidación, amarilleo y aparición de manchas puntuales. Por este motivo en la actualidad sólo utiliza un barniz mate de la casa Lascaux ${ }^{\circledR}$. Por otro lado, para conseguir el acabado homogéneo y mate tan deseado, barniza utilizando un compresor potente que atomiza las partículas.

Al ser preguntado por la importancia de la apariencia de la superficie el artista señala que es un elemento añadido más de la expresión artística: "[...] que la superficie sea brillante o mate hace variar completamente la obra" (J.M. Yturralde, comunicación personal, 6 de mayo, 2006).

Es evidente que el paso del tiempo sobre la materia de la obra afectará a los matices y tonos seleccionados por el artista. Sin embargo, no menciona que éste sea un problema importante; sí lo sería sin embargo, el cambio del aspecto mate a brillante de los acabados.

Un problema grave que puede producirse tendría que ver con las alteraciones mecánicas de las superficies: grietas, erosiones, repintados puntuales... problemas habituales dada la naturaleza de sus pinturas. Ante un problema concreto de grietas sobre la superficie de una obra, el artista sugirió el repintado total de la superficie, “[...] los clavos y sus alteraciones en la superficie destruyen la obra más que el leve cambio de color o tono" (J.M. Yturralde, comunicación personal, 6 de mayo, 2006).

$\mathrm{Al}$ analizar cómo el paso del tiempo afectará a la condición de la materia, y entendiendo que este proceso es inevitable, hemos conseguido concretar dos aspectos esenciales en la obra del artista. Por un lado, la necesidad de preservar el aspecto mate de la superficie, aspecto que el propio artista señala como fundamental. De otro, la necesidad de obtener una superficie plana, homogénea, sin daños mecánicos ni interrupciones cromáticas. Cabría señalar por último que no sería tan importante para el artista una pequeña variación del tono, como él mismo ha señalado.

En este caso, el artista se ha visto en la necesidad de rehacer, reelaborar, reeditar, repintar o repristinar la materia de algunas de sus obras, dada la fragilidad de los acabados y la aparición relativamente fácil de daños mecánicos en las superficies, y dada la presión del mercado del arte y las poco apropiadas medidas de conservación preventiva que en ocasiones sufren las obras. La "repristinación" es la intervención de intromisión manual total de la obra con la intención de recuperar de manera mimética el verdadero (o presunto) aspecto original. Sería un acto censurado por Cesare Brandi, (Basile, 2007: 81). 
Al analizar este hecho, encontramos varias cuestiones interesantes. En primer lugar, que para el artista, puesto que él mismo lo ha llevado a cabo, el repintado total de la superficie no afecta a la autenticidad de la obra, como en el caso de la obra Prisma 4 (Soraluze/Llamas, 2008:111-116), aunque es cierto que en aquella ocasión la intervención fue realizada por el propio artista. Y tampoco es importante este hecho para el mercado del arte, que acepta la obra reeditada como original, siempre que sea la mano del artista quien ejecute la reelaboración.

Cabe reflexionar sobre hasta qué punto el mismo proceso realizado por otra persona afectaría a la autenticidad de las creaciones, y podríamos señalar que probablemente en ese caso, el mercado del arte no la aceptaría del mismo modo.

Y con todo, según Yturralde, había llegado un momento en que ya no podía seguir reeditando las obras una y otra vez, dada la necesidad de frescura de sus superficies, por lo que ante la cuestión de quién debería intervenirlas acabó aceptando que lo hicieran los conservadores bien cualificados.

¿Pero esa intervención debería ser tan atrevida como la que haría el propio artista? ¿Sería afectada la obra en su autenticidad si el conservador la reeditara tal y como lo hizo el artista? Sin embargo ¿cómo preservar los valores esenciales de la obra, en el caso de que éstos estén depositados en la homogeneidad del color, sin realizar la mencionada reedición?

Sería importante reflexionar sobre la evolución del objeto artístico en la actualidad y sobre dónde radica la autenticidad de la obra, en su concreción material, o en el proyecto y el plano conceptual, pues para este caso el propio artista señala que la reedición no supone para él ningún problema de tipo ético: “[...] he rehecho muchas figuras imposibles porque se trataban muy mal" (J.M. Yturralde, comunicación personal, 6 de mayo, 2006).

¿Radicaría la autenticidad del objeto artístico contemporáneo en la unicidad del mismo, como ocurre para el arte tradicional? ¿Cuán importante sería la mano del artista en un proceso de reedición? Y, dado que el propio artista señala que las intervenciones sobre su obra deberían hacerlas los restauradores cualificados, ¿qué tipo de actuaciones podrían llevar cabo?

\section{La materia y su significación en la obra de Miquel Barceló}

Otro de los artistas que ha sido entrevistado es Miquel Barceló. ¿Cómo utiliza la materia este artista? ¿Cómo concibe el paso del tiempo sobre su obra? ¿Cuál es la significación de la materia en relación con la intención artística?

El propio artista señala cómo comenzó su relación con la materia en una entrevista realizada por Rosario Llamas y M ${ }^{\mathrm{a}}$ Carmen Talamantes en 2011: "Cuando tenía 18 o 19 años me encontraba estudiando Bellas Artes y empecé a interesarme por todo eso de la evolución de la materia... empecé a trabajar en una serie de quince cajas de madera que contenían carne, unos elementos que iban pudriéndose, se trataba de provocar, de pintar con los enemigos de la pintura..." (M. Barceló, comunicación personal, 17 de noviembre, 2011). En este momento, el conflicto del artista en relación con la intención plástica se refería a la necesidad de realizar, como él apunta, la antipintura. Sin embargo, el uso de materiales orgánicos o perecederos que se degradaban intencionadamente, no significaba que no estuviera elaborando pintura igualmente, 
pues los materiales eran usados con una intención pictórica. "[...] finalmente, me di cuenta de que todo era pintura, aunque cambiase de materiales no dejaba de ser pintura. En aquellos momentos no se podía pintar. Lo moderno, lo que se llevaba, era la anti-pintura y yo estaba haciendo pintura... que no era pintura, porque terminaba pudriéndose, pero lo parecía. Pensé: me estoy haciendo trampa a mí mismo".

Analizando la relación inicial del artista con la pintura, Barceló apunta que "[...] en ese momento pretendía pintar con elementos que estaban en contra de la pintura, los elementos negativos, el agujero negro, la antimateria. Empleaba oxidaciones, ácidos, pelos..."

En este caso es importante el uso de elementos que tradicionalmente son entendidos como imperfecciones, pero que para Barceló son útiles como agentes plásticos; en el caso de la cerámica, por ejemplo, emplea las grietas casi como un elemento gráfico intencionado; en pintura, las arrugas, las grietas o los agujeros se convierten en tema de sus obras: "[...] yo decidí pintar precisamente con todo eso: oxidaciones, grietas, craquelados... Todo lo que se considera defecto yo lo usaba como mi paleta."

La relación con el paso del tiempo y su efecto sobre la materia no parece ser conflictiva para el artista, más bien es utilizado de manera premeditada y con un fin estético. Preguntado sobre este proceso inevitable, el artista señala: "[...] siempre me ha interesado el tema de la longevidad y de la perennidad de la obra de arte. Muchas veces es el tema de fondo de la obra y, en otras, es la forma. Me gusta pensar en el tiempo geológico" Y por otro lado, está presente en muchas de sus obras el aspecto procesual: muchas incluyen el paso del tiempo como un elemento configurador de la obra de arte, constructor y necesario para llegar por fin al descubrimiento, casi como el agente revelador. Podemos poner como ejemplo la serie de retratos dibujados gracias al efecto oxidante de la lejía. El artista dibuja-pinta en un proceso sustractivo que será apreciable tras la acción de este agente: "[...] hago trabajos con mucha materia y, al mismo tiempo, realizo otros con muy poca, o casi sin materia, como las obras que hago con humo. Estas obras no tienen nada de materia. Son obras realizadas con lejía sobre tela negra. Es la antimateria". Estas obras fueron expuestas en la Galería Acquavella de New York del 8 de octubre al 22 de noviembre de 2013.

Otros proyectos mencionados por el artista podrían ilustrar este punto. Barceló nos explica que tiene intención de realizar una nueva versión de su famoso elefante, pero en esta ocasión en bronce con una imprimación recubierta de excrementos y barro. La idea consistiría en ir observando el cambio de la apariencia de la obra al ir desapareciendo debido al paso de los años, cada una de las capas, hasta llegar al bronce del interior. De nuevo el paso del tiempo entendido como un agente configurador que nos permite observar la evolución, mutación o transformación de la obra. No cabría en este caso intentar congelar una apariencia única de la misma, pues todas las incluidas en el proceso serían auténticas.

Sin embargo, también realiza obras en las que el elemento procesual no está incluido, y entonces el artista deja entrever su preocupación por el uso de materiales estables y de calidad, que presenten un buen comportamiento a través de los años. Este sería el caso de la obra realizada para la decoración de la cúpula de la Sala de los Derechos Humanos y de la Alianza de Civilizaciones en el Palacio de las Naciones Unidas de Ginebra. En esta obra, apunta, "[...] empleamos una resina 
vinílica. Estuvimos trabajando junto con restauradores para todo lo que era el tema del control de materiales".

En relación con la apariencia de las obras, algunas cuestiones son esenciales. El propio artista señala: "[...] mis obras son muy mates, nunca las barnizo, odio los barnices. Cuando restauran las obras, suelen poner un barniz de restaurador, un barniz repugnante. Si lo ponen, siempre pido que lo eliminen. También les pido que quiten el marco si lo hay".

Cabe señalar que Barceló muestra su descontento con algunas intervenciones de restauración, de modo que únicamente está dispuesto a que se les quite el polvo a sus obras y a que se controlen las condiciones de conservación preventiva con el fin de evitar la degradación.

\section{La materia y su significación en la obra de Juan Genovés}

Analizaremos a continuación la intención artística de otro creador importante del panorama nacional. El artista Juan Genovés formó parte del grupo Hondo en los años sesenta, junto con Fernando Mignoni y José Paredes Jardiel. Este grupo irrumpió como una opción que intentaba superar los modelos expresionistas del grupo El Paso, así como las propuestas normativas y frías del momento. Su particularidad estuvo en que el grupo Hondo optó por una nueva figuración, pero sin romper del todo con las raíces informalistas (Guash, 1997: 137).

Si por algo se caracterizó la producción del grupo Hondo, fue por aportar al panorama español una serie de obras con argumento, donde reivindicaban la presencia del hombre y de su huella en medio de la maraña informal (Haro, 2010: 59). Este arte con argumento favoreció la comunicación entre pintura, hombre y arte, adaptándose al contexto social de la época y generando cierto desasosiego sobre el espectador (Vergniolle, 2008: 308-313).

Tenemos la oportunidad de analizar una de las entrevistas al artista, realizada el 20 de octubre de 2010 en Aravaca, Madrid, por $\mathrm{M}^{\mathrm{a}}$ Carmen Talamantes en el marco del proyecto de investigación del Ministerio HAR2008-03444.

Juan Genovés insistió a lo largo de toda la entrevista en la importancia que para él tiene la buena conservación de sus obras. Considera fundamental que los materiales se comporten bien y sus colores permanezcan inalterados, pues la saturación de los mismos es absolutamente esencial para el artista. La pérdida de intensidad cromática afecta a la significación de sus creaciones ya que como expresa: "[...] para mí la pintura debe durar" (J. Genovés, comunicación personal, 20 de octubre, 2010).

Preguntado por la importancia del material en relación con la significación de la obra explica: "[...] quiero que dure al máximo, pero sin que coarte mi trabajo. No quiero que sea mayor el interés de que perdure, a mi creación. Me gusta que mis creaciones estén latentes, que estén vivas, y por eso, un cuadro retocado no me gusta. Quiero conservar la viveza de los materiales, por eso elijo los mejores".

Podríamos reflexionar en este punto sobre dos cuestiones importantes y muy habituales en el discurso de los artistas contemporáneos. Para Genovés la calidad de los materiales que utiliza es fundamental, una exigencia que le lleva a hacer por sí mismo pruebas de envejecimiento de los colores, con el fin de comprobar su 
estabilidad ante la luz y para elegir, dentro de las posibilidades económicas de cada momento, la gama de materiales de mayor calidad. Sin embargo, como apunta, el hecho creativo estará por encima de cualquier otra circunstancia.

En el caso de Juan Genovés el efecto del paso del tiempo sobre la materia es preocupante "sé que con el paso del tiempo el color azul intenso desaparecerá y ya pinto con la idea de que este azul será más grisáceo, por eso pinto las figuras de un negro más intenso". El artista conoce que algunos colores pueden aclararse, o que las telas sobre las que pinta directamente podrán oscurecerse y amarillear "[...] una tela de algodón con el tiempo oscurecerá, así que todo está previsto". Es obvio que ha reflexionado sobre este hecho, que afectará negativamente a la apariencia de las obras y en consecuencia a la significación, y es evidente su preocupación por que las obras envejezcan bien. Para el artista las obras deben estar vivas, con colores vibrantes: "[...] hago mis propias pruebas con los materiales que empleo, por eso sé cómo envejecerán, los tengo comprobados".

Por otro lado, resulta especialmente interesante su uso reiterativo del concepto de muerte de la obra (Althöfer, 2003: 11). Ya hemos hablado sobre la ruina en el arte contemporáneo, sobre la posibilidad de encontrar obras en las que el paso del tiempo ha afectado irreversiblemente a su capacidad de trasmitir el discurso estético. En este sentido Genovés señala: "[...] no hay cosa que me deprima más que ver una obra agotada, muerta". También el artista contemporáneo es consciente de que este hecho se puede producir, Genovés apunta a la decadencia y la muerte de las obras como algo posible, experimentado por él mismo: "[...] cuando fui a Nueva York en el '67 y vi las obras del Pop Art...fíjate que sólo las conocía por reproducciones, y por ellas habían trascurrido sólo cinco años; pues cuando las vi estaban como muertas, la materia estaba ya vieja".

Y ante este temor confía en que la mayoría de sus colores tendrán un buen comportamiento. Genovés ha seleccionado los mejores materiales, ha realizado pruebas personales de envejecimiento, se ha preocupado por hacer todo lo posible para que sus obras no se alteren con el paso del tiempo, hasta ha calculado las posibles alteraciones cromáticas de algunos colores para tenerlas en cuenta. Y todo ello porque en su obra, el paso del tiempo, la degradación y alteración cromática sí alterará y afectará a cuestiones esenciales: “[...] confío en que el cuadro esté vivo dentro de muchos años aunque la tela haya amarilleado un poquito. A mí no me gustaría que envejecieran. Lo que sí me importa es que lo que pinte encima de la tela se mantenga vivo y con fuerza..."

La técnica actual del artista (pinta con acrílicos directamente sobre la tela pegada a un contrachapado) es fruto de una evolución personal, de un esfuerzo por conseguir un objeto duradero y estable que mantenga una apariencia fresca y viva durante el mayor tiempo posible. Podríamos insistir en que resulta especialmente interesante observar cómo desde el mundo de la creación artística se utiliza el término de muerte de la obra ante la presencia de una materia que no es capaz de cumplir con su función inicial. Genovés asume y entiende sin ningún tipo de pudor que la condición de la materia puede afectar gravemente al plano semántico, encontrándonos en este caso ante la ruina de la obra, una ruina no deseada, convertida en icono, mitificada en muchos casos, una ruina difícil de asumir en el mundo del arte y el de la conservación. 


\section{La materia y su significación en la obra de Miquel Navarro}

Miquel Navarro es un escultor valenciano nacido en 1945 en la localidad de Mislata, Valencia. En la actualidad mantiene su estudio en el barrio de la morería, donde nació, allí se produjo la entrevista con el artista.

Desde los años setenta, momento a partir del cual se dedica exclusivamente a lo tridimensional, su obra presenta una visión pluralista de la escultura (Guash, 2000: 309-310). Influenciado por el constructivismo ruso y la obra de Julio González, se decanta por el material refractario, haciendo uso de volúmenes simples inspirados en las ciudades industriales, los cuales se disponen en el espacio con un orden marcadamente urbanístico.

Resaltaremos de nuevo los aspectos que más nos interesan en esta investigación: el uso y significado de la materia en su obra, y los efectos del paso del tiempo sobre la misma, con el fin nuevamente de conocer dónde reside lo esencial en sus creaciones.

Durante la conversación con el artista se aprecian algunas preocupaciones en relación con la autenticidad de las piezas, la importancia de la mano del artista y la originalidad de las obras. Al hablar sobre la importancia de la materia, el artista resalta que la idea está ligada a un material específico en la medida en que ése es el idóneo para concretarla. Esta afirmación subraya de nuevo la importancia que tiene la elección del tipo de material, tanto por servir de sostén físico, como por estar dotado de una carga simbólica.

En relación con el paso del tiempo, Miquel Navarro apunta: “[...] a mí sí me importa el paso del tiempo y por eso utilizo el barro. Lo utilizo porque he descubierto que el barro es uno de los materiales que más dura, al igual que la piedra y los metales nobles" (M. Navarro, comunicación personal, 18 de octubre, 2010). Así, la duración a largo plazo de sus obras le preocupa y por eso utiliza materiales considerados nobles como el barro, los metales, la cerámica o la piedra. El propio artista vincula el uso del barro con sus experiencias de niñez. La zona donde vivió sufría inundaciones debidas al crecimiento del río Turia, y los niños iban a recoger el barro tras las crecidas. Se trata por otra parte de una zona con gran tradición ceramista: muy cerca se encuentran las fábricas de cerámica valenciana de Manises, Paterna, Quart de Poblet o la propia Mislata, que se establecieron a partir del siglo XV.

Los materiales son empleados desde el punto de vista de un escultor, como podría ocurrir en el caso de la cerámica, pues son utilizados para construir volúmenes y formar parte de un espacio.

En relación con el resto de materiales, Miquel Navarro explica que, aunque ha utilizado el acero corten, no es su material preferido. Y esto no por su comportamiento (la transformación de las superficies), o su apariencia, sino porque según él, es un material ampliamente empleado por los artistas, que homologa los lenguajes plásticos y no redunda en la originalidad y creatividad propias. Navarro muestra su preocupación por conseguir un lenguaje plástico único, discernible, que no pueda confundirse con el de otro artista. Por este motivo, aunque utiliza el hierro ampliamente, éste es recubierto con una capa de pintura que lo dota de una carga semántica y estilística específica.

En cuanto a materiales como el aluminio, explica que es un elemento que remite a lo industrial, aspecto presente por otra parte en muchas de sus obras como eje 
vertebrador, y que también remite a la utopía científica. El aluminio nos dirige hacia la ciencia ficción, y la cerámica y el hierro, a aspectos más cálidos. En cuanto a los acabados, explica que los de las piezas de aluminio son muy costosos y laboriosos, y que deberían ser conservados.

La apariencia de las obras va ligada al concepto, los acabados son trabajados, seleccionados, estudiados a priori. El paso del tiempo va a actuar sobre los metales y este proceso requiere de una reflexión necesaria por parte del artista: "No me molesta el paso del tiempo en el hierro y tampoco me molesta cuando una pintura ha perdido intensidad, como por ejemplo en el caso del Parotet, que tiene ahora una tonalidad más clara que cuando lo hice". La obra, pintada de azul desde el principio, se recorta contra el cielo luminoso de la ciudad de Valencia e interacciona integrándose con él incluso en varios momentos del día. Con el tiempo el color ha ido palideciendo y perdiendo intensidad, pero según apunta el artista, este hecho no le importa, pues continúa interaccionando contra el azul del cielo de igual manera.

Sin embargo, llegado el momento y cuando la obra lo requiera, el artista entiende como algo perfectamente lógico que se vuelva al color original. Navarro apunta que lo que más le molestaría sería el abandono consciente de la obra, su falta de mantenimiento, en definitiva, el olvido: “... más grave es que la Pantera Rosa [una fuente pública en la ciudad de Valencia] tenga una pintada en la parte de abajo desde hace, por lo menos siete años, y que nadie haya pensado en repintarla".

Es obvio que el artista se muestra extremadamente preocupado por la falta de conciencia de conservación; cree en la restauración, pero insiste en que ésta no puede convertirse en ningún caso en recreación. Navarro deja patente que la restauración debe ser respetuosa con el original: "[...] las esculturas que yo he realizado para la calle, no están construidas para ser efímeras: las he hecho para el disfrute de la contemporaneidad."

Y ante la necesidad de repintar las obras dentro de un plan de mantenimiento deseado por el artista, y dada la repercusión que este hecho podría tener sobre la autenticidad de las piezas, preguntamos al artista si el repintado de las superficies podría llegar a afectar a la originalidad de las obras, hecho que no preocupa al artista.

Por otro lado, sus instalaciones están formadas por multitud de piezas que pueden alterarse o perderse. En este caso se plantea la posibilidad de sustitución de estos elementos, la sustitución de elementos de tipo funcional es una intervención adecuada si se realiza un correcto estudio previo (Chiantore/Rava, 2005: 51), ante lo cual el artista estaría de acuerdo, indicando incluso que no sería necesario que él mismo rehiciera las piezas: "[...] el restaurador no debe inventarse nada, pero con una documentación exhaustiva sí puede realizar la copia".

De nuevo nos encontramos con que los propios artistas no consideran necesario que sean ellos quienes realicen las reediciones: su mano, tan importante para el mercado del arte, sería algo anecdótico: "[...] en mis ciudades hay muchas piezas que se repiten, por lo tanto yo mismo asimilo la repetición".

Por concluir, las obras de Miquel Navarro han sido entendidas y asimiladas por el gran público. Encontramos en ellas valores culturales y sociales, además de los propiamente estéticos. Se trata de obras conocidas en el entorno urbano, forman parte del ideario colectivo, son motivo de comentarios entre los habitantes de la ciudad y 
obviamente, han adquirido el derecho a ser conservadas. En el caso del arte público, el repintado de las esculturas formaría parte de un plan de mantenimiento necesario y deseado. Aunque lo esencial de las obras no se vea afectado por la degradación de las capas de pintura o de los recubrimientos, sí que es necesario un plan de mantenimiento adecuado que garantice el respeto por la intención artística: el disfrute de las mismas en el momento actual.

\section{La materia y su significación en la obra de Equipo Crónica}

Por último estudiaremos el caso de Equipo Crónica. La intención artística de Equipo Crónica fue la de vincularse con la Modernidad, y en los años sesenta ésta pasaba por la práctica del Pop Art. Sin embargo, la Nueva Figuración, la Peinture Politique, no pretendió, como en el caso americano, evocar la sociedad de la abundancia o poner de manifiesto el American Way of Life, sino que pretendió hacer visible desde una óptica Pop una mirada crítica hacia el entramado social, para poner de relieve sus desequilibrios (Solbes/Llamas, 2010: 27-49).

En relación con la materia, mucha de su producción se realizó como obra seriada, utilizando el linóleum, la serigrafía o la litografía, técnicas que facilitaban la difusión de su trabajo haciéndolo más asequible al público al cual iba dirigido. Su lenguaje claro y directo jerarquizó las figuras y eliminó la expresividad de las texturas, esfumados, y trasparencias, con la intención de simplificar la lectura: "Se buscaba una pintura directa que no centrara la atención del espectador en aspectos de alarde técnico y que condujera concisamente hacia el tema a abordar... para que la percepción de la carga semántica fuera directa" (Patuel, 2001: 361-373).

Estos procedimientos compositivos se canalizaron a través de una técnica también moderna: a través del uso de las pinturas de emulsión acrílica, utilizadas tanto en su producción bidimensional como tridimensional. Su uso estuvo influenciado por el arte Pop internacional, y fue del agrado de Equipo Crónica dada la posibilidad de obtener acabados mates de las superficies, colores planos y sin texturizar. El uso de las pinturas acrílicas es muy útil en este sentido y fue su material por excelencia hasta la introducción de los óleos en su última etapa. Con el acrílico se pueden crear grandes zonas homogéneas de color, no deja la huella del pincel, no produce brillos y permite realizar correcciones rápidas. Sin embargo presenta el problema de su alta sensibilidad a la suciedad superficial. La capacidad de atraer e incorporar la suciedad acumulada que tiene la película acrílica se debe a su baja temperatura de transición vítrea $(\mathrm{Tg})$, que está muy cerca de la temperatura ambiente $\left(20^{\circ} \mathrm{C}\right)$. Éste es un factor de deterioro muy importante que estaría directamente relacionado con el aspecto final de la obra, con la apariencia y percepción de los colores, y por consiguiente con la percepción y lectura de la misma. La capa pictórica en condiciones de alta temperatura se vuelve muy viscosa y blanda; a temperaturas bajas, la película se vuelve dura y quebradiza, se produce la pérdida de la elasticidad natural del acrílico, y se favorece la aparición de craquelados y agrietamientos (Learner, 2004: 5).

Hemos visto que en el caso de Equipo Crónica la idea de la obra se trasmite a través de la imagen, y que la función de la materia es vehicular, pues se ha descargado de cualquier tipo de connotación plástica. Lo esencial en la obra de Crónica es la comunicación a través de la imagen, de modo que el paso del tiempo tendrá un impacto 
negativo sobre su lectura. El agrisado de las superficies debido a la acumulación del polvo en suspensión y la aparición de las patologías habituales en estas obras se convertirán en ruido en ese proceso de comunicación.

En cuanto a la importancia de la mano del artista, también en este caso queda desmitificada, pues los componentes de Equipo Crónica trabajaron con ayudantes en la realización de las series de los múltiples y manifestaron su gusto por el trabajo en equipo, colaborativo y experimental, y por ello, hicieron uso de métodos colectivos de trabajo que les permitieran alcanzar un fin más alto y sobreindividual.

En todo caso, y ya que debemos ante todo facilitar la lectura social, crítica y reivindicativa de sus obras como elemento esencial de las mismas, y puesto que en muchas de ellas trabajaron ayudantes, podrían plantearse intervenciones de conservación que fueran respetuosas, pero que tuvieran como fin último y prioritario, garantizar esa lectura. Podríamos valorar que, , "[...] cuando lo que se pretende es salvar la idea, que tiene su razón de ser en la homogeneidad de la superficie [hablando sobre una obra de Ad Reinhardt], es necesario pasar por alto los criterios de conservación [refiriéndose a los tradicionales] y trabajar con un sentido más amplio" (Schinzel, 2003: 19).

\section{Conclusiones}

La materia forma parte de la obra de arte contemporáneo, al menos, en la mayoría de los casos. Los artistas concretan sus creaciones haciendo uso de cualquier tipo de material artístico que esté a su alcance. Cada artista dota a esta materia, seleccionada y manipulada por él mismo, de unas connotaciones semánticas específicas. Sin embargo, el paso del tiempo tendrá su efecto sobre los acabados superficiales y los matices cromáticos; en ocasiones, la materia pobre y perecedera, se transformará rápidamente.

La documentación del plano conceptual de la obra incluye las entrevistas con los artistas. En estos encuentros debe prestarse especial interés por concretar cuáles son los aspectos esenciales de las obras, los que no pueden verse alterados con el paso de los años, para determinar si el cambio o mutación, inevitable, afecta a lo esencial en cada caso y por lo tanto, para determinar el estatus del objeto artístico. El artículo ha estudiado, para el caso de algunos artistas importantes del panorama español, cómo es entendida la materia en relación con la significación de la obra.

La creación artística es un fenómeno cultural, está relacionada con diversas disciplinas y no puede entenderse como un fenómeno aislado. Del mismo modo, la conservación y restauración del arte contemporáneo debe estarlo también, no debe desvincularse de la necesidad de elaborar un pensamiento crítico. La necesidad de reflexión teórica en el ámbito de la conservación del arte contemporáneo es evidente, y ello porque el conservador se sitúa ante situaciones impredecibles para teóricos anteriores, el acercamiento hacia la filosofía, la teoría crítica, o la antropología se hace imprescindible.

La necesidad de conservar la memoria ha sido tratada por diferentes pensadores que han puesto de manifiesto el surgimiento de un fuerte interés por conservarla como elemento cultural y político (Nora, 1984-1992; Huyssen, 2002), quedando en épocas pasadas el interés por centrar el foco en el imaginario del futuro. Sin embargo, no es 
éste el único planteamiento que a través de la documentación de la obra de arte actual debe abordar el conservador. Al documentar la obra, al comprenderla y concretar en qué consiste exactamente, el conservador contribuye a perpetuar la historia, a configurar el pasado y legarlo al futuro, pero pensar únicamente en estos términos sería insuficiente. La documentación de la obra, que incluye el estudio semántico de la misma, no pretende sólo perpetuar la memoria, sino trasmitir nuestro patrimonio al futuro. Un patrimonio que está formado por obras cuya materia puede degradarse rápidamente o simplemente ser repuesta periódicamente. Es cierto que habrá ocasiones en las que el conservador se verá liberado de la necesidad de conservación, ante obras efímeras por voluntad del artista, creadas o no con esa intención. Pero en otras, se verá obligado a legar el patrimonio actual como una necesidad antropológica, un patrimonio que consta en ocasiones de obras únicamente proyectas.

La creación artística ha situado al conservador ante situaciones complejas pues no sólo debe conservar un patrimonio que se realizó en un lugar y momento determinado, sino que debe atender a la evolución de la obra a través del tiempo, una evolución premeditada, que forma parte del concepto artístico y que sitúa a la obra en diversos futuros que serán presentes. ¿Cómo podemos abordar el estudio de la temporalidad en obras que se reconstruyen para cada exposición y que disfrutan de un eterno presente?

En relación de nuevo con el boom por conservar la memoria acaecido en los últimos años, cabe insistir en que el restaurador, para el caso del arte contemporáneo no pretende en ocasiones conservar el recuerdo de la obra, sino la obra misma. Esta intención primordial de la disciplina le obliga a analizar el concepto de autenticidad y a revisarlo continuamente. Desde el objeto único, dotado de aura y con valor de culto descrito por Benjamin, pasando por el estudio de los valores estéticos e históricos prioritarios para Brandi, debemos acercarnos en la actualidad a la posibilidad de reedición, de actualización y mutación continua del objeto contemporáneo, y estudiar en qué modo afectará este hecho a la autenticidad de nuestro patrimonio.

Este sentido tradicional del término, válido para épocas anteriores, no puede aplicarse a los objetos actuales, pues si la autenticidad va ligada al aura, al carácter irrepetible del objeto y a su historia material, entonces no podríamos decir que una obra de Sol Lewit, materializada en cada nueva exposición fuera auténtica, pues para este caso, en añadidura, no es la mano del artista quien la vuelve a reeditar.

\section{Referencias}

Aguilera V. (1975). La posguerra: documentos y testimonios. Madrid: Ministerio de Educación y Ciencia.

Aliaga, J.V. y García, J.M. (1998). Pintura y escultura del segle XX. En Història de l'Art al País Valencià (pp.179-319) vol.III. València: Eliseu Climent (ed).

Althöfer, H. (2003). Restauración de pintura contemporánea. Tendencias, materiales, técnica. Madrid: Akal.

Bal, M. (2002). Conceptos viajeros en las humanidades. En Travelling concepts in the Humanities. Toronto: University of Toronto Press.

Basile, G. (2007). Teoria e Pratica del restauro in Cesare Brandi. Prima definizione dei termini. Saonara: Il Prato. 
Barreiro, P. (2009). La abstracción geométrica en España (1957-1969). Madrid: CSIC.

Benjamin, W. (2003). La obra de arte en la época de su reproductibilidad técnica. México, D. F.: Itaca.

Chiantore O. y Rava A. (2005). Conservare l'arte contemporánea. Milán: Electa.

Colombo, G. (2005). Instalaciones y pasado remoto. En Righi, L. (2005). Conservar el arte contemporáneo (pp. 113-120). Donostia: Nerea.

Escohotado, T. (2007). La problemática de la obra de arte contemporáneo. En Macarrón, A.M. y González, A., La Conservación y Restauración en el siglo XX, pp. 199-208. Madrid, Tecnos/Alianza.

Guash, A. M. (1997). El arte del siglo XX en sus exposiciones. 1945-1995. Barcelona: Ediciones del Serbal.

Guash, A. M. (2000). El arte último del siglo XX. Del posminimalismo a lo multicultural. Madrid: Alianza Forma.

Haro, N. (2010). Grabadores contra el franquismo. Madrid: CSIC.

Huyssen, A. (2002). Presentes: los medios de comunicación, la política, la amnesia. En Global-local: democracia, memoria, identidades (pp. 217-237). Montevideo: Trilce.

J.M. Yturralde, (comunicación personal) (2006, 6 de mayo).

J. Genovés, (comunicación personal) (2010, 20 de octubre). Entrevista realizada por M.C. Talamantes.

Learner, T. (2004). Analysis of Moden Paints. Los Ángeles: The Getty Conservation Institute.

Llamas, R. (2014). Arte contemporáneo y Restauración. O cómo investigar entre lo material, lo esencial y lo simbólico. Madrid: Tecnos.

Muñoz, S. (2003). Teoría contemporánea de la restauración. Madrid: Síntesis.

M. Navarro, (comunicación personal) (2010, 18 de octubre).

Nora, Pi. (dir.) (1984-1992). Les Lieux de mémoire. Paris: Gallimard.

Patuel, P. (2001). Arte y compromiso social en la España del siglo XX. En Cabañas, M. El arte español del siglo XX: su perspectiva al final del milenio. X Jornadas de Arte (pp. 361-374). Madrid: Consejo Superior de Investigaciones Científicas.

Barceló, M. (comunicación personal) (2011, 17 de noviembre).

Schinzel, H. (2003). Restauración e investigación. Un intento de esquematización. En Althöfer, H. Restauración de pintura contemporánea. Tendencias, Materiales, técnicas (pp. 19-26). Madrid: Akal.

Solbes, A. y Llamas R. (2010). Conservar la obra de Equipo Crónica. Estudio de la idea y la materia, en AA.VV. Conservación de Arte Contemporáneo, $11^{a}$ Jornada (pp. 27-47). Madrid: Museo Nacional Centro de Arte Reina Sofía.

Soraluze, I. y Llamas, R. (2008). When the intellectual univers of a work of art prevails over the authenticity of its physical structure. Arché, n³, pp.111-116.

Vergniolle, M. (2008). La palabra en silencio: Pintura y oposición bajo el franquismo (pp. 308-313). Valencia: Universidad de Valencia. 